\title{
Development of a new marker system for identifying the complex members of the low-molecular-weight glutenin subunit gene family in bread wheat (Triticum aestivum L.)
}

\author{
Xiaofei Zhang • Dongcheng Liu $\cdot$ Wenlong Yang $\cdot$ Kunfan Liu $\cdot$ Jiazhu Sun • \\ Xiaoli Guo $\cdot$ Yiwen Li $\cdot$ Daowen Wang $\cdot$ Hongqing Ling $\cdot$ Aimin Zhang
}

Received: 4 August 2010/Accepted: 5 February 2011/Published online: 23 February 2011

(C) The Author(s) 2011. This article is published with open access at Springerlink.com

\begin{abstract}
Low-molecular-weight glutenin subunits (LMW-GSs) play an important role in determining the bread-making quality of bread wheat. However, LMW-GSs display high polymorphic protein complexes encoded by multiple genes, and elucidating the complex LMW-GS gene family in bread wheat remains challenging. In the present study, using conventional polymerase chain reaction (PCR) with conserved primers and high-resolution capillary electrophoresis, we developed a new molecular marker system for identifying LMW-GS gene family members. Based on sequence alignment of 13 LMW-GS genes previously identified in the Chinese bread wheat variety Xiaoyan 54 and other genes available in GenBank, PCR primers were developed and assigned to conserved sequences spanning the length polymorphism regions of LMW-GS genes. After PCR amplification, 17 DNA fragments in Xiaoyan 54 were detected using capillary electrophoresis. In total, 13
\end{abstract}

Communicated by J. Snape.

X. Zhang and D. Liu contributed equally to this work.

Electronic supplementary material The online version of this article (doi:10.1007/s00122-011-1550-7) contains supplementary material, which is available to authorized users.

X. Zhang · D. Liu $\cdot$ W. Yang $\cdot$ K. Liu $\cdot$ J. Sun $\cdot$ Y. Li ·

D. Wang $\cdot$ H. Ling $\cdot$ A. Zhang $(\bowtie)$

State Key Laboratory of Plant Cell and Chromosome Engineering, National Center for Plant Gene Research, Institute of Genetics and Developmental Biology,

Chinese Academy of Sciences, 1 West Beichen Road,

Chaoyang District, Beijing 100101, China

e-mail: amzhang@genetics.ac.cn

X. Guo

College of Biology, China Agricultural University,

Yuanmingyuan Xi Lu 1, Haidian District, Beijing 100193, China fragments were identical to previously identified LMW-GS genes, and the other 4 were derived from unique LMW-GS genes by sequencing. This marker system was also used to identify LMW-GS genes in Chinese Spring and its group 1 nulli-tetrasomic lines. Among the 17 detected DNA fragments, 4 were located on chromosome $1 A, 5$ on $1 B$, and 8 on $1 D$. The results suggest that this marker system is useful for large-scale identification of LMW-GS genes in bread wheat varieties, and for the selection of desirable LMW-GS genes to improve the bread-making quality in wheat molecular breeding programmes.

\section{Introduction}

Bread wheat (Triticum aestivum L., AABBDD, $2 n=6 x=42$ ) can be processed into bread, pasta, noodles and other food products due to its unique dough viscoelastic properties. These biochemical properties are mainly conferred by seed storage proteins (Shewry et al. 1995; Weegels et al. 1996) called prolamins, comprising two major groups-gliadins and glutenins-based on their different solubilities in alcohol-water mixtures (Osborne 1924). Wheat glutenins are classified as high-molecularweight glutenin subunits (HMW-GSs) and low-molecularweight glutenin subunits (LMW-GSs) according to their mobility during sodium dodecyl sulphate polyacrylamidegel electrophoresis (SDS-PAGE; Payne 1987; Gupta and Shepherd 1990). These glutenin subunits are polymerised by intermolecular disulphide bonds, which contribute to the viscoelastic and extensible properties of dough and consequently influence the quality of wheat food products (Shewry et al. 1995). Thus, the characterisation of specific HMW-GS and LMW-GS genes encoding these glutenin subunits was highlighted in the improvement of wheat 
quality (Payne 1987; Gupta et al. 1989, 1991; Metakovsky et al. 1990). HMW-GSs have been extensively investigated because of their importance in dough strength and their relative simplicity at the DNA and protein levels (Shewry et al. 1995). Unlike HMW-GSs comprising three to five members in a bread wheat variety, LMW-GSs display high polymorphic protein complexes encoded by a multigene family. Generally, these genes are located at the Glu-A3, Glu-B3 and Glu-D3 loci on the short arms of chromosomes $1 A, I B$ and $1 D$, respectively (Singh and Shepherd 1988; D'Ovidio and Masci 2004). The total gene copy number was estimated to vary from 10-15 (Harberd et al. 1985) to 30-40 (Sabelli and Shewry 1991; Cassidy et al. 1998) in hexaploid wheat based on Southern hybridisation analysis. However, the exact copy number of LMW-GS genes is still unknown, mostly due to lack of efficient methods to distinguish members of this multigene family. Even so, several hundred LMW-GS genes have been isolated from bread wheat and its relatives because of their significant effect on dough strength and extensibility (D'Ovidio and Masci 2004). Based on LMW-GS sequences deposited in GenBank (http://www.ncbi.nlm.nih.gov/), the primary structure of a typical LMW-GS has been proposed: a signal peptide of 20 amino acids, a short $\mathrm{N}$-terminal domain (13 amino acids), a central repetitive domain and a C-terminal domain, which is further subdivided into three distinctive regions-namely, C-terminal I, II and III (D'Ovidio and Masci 2004). Sequence alignment has indicated that the signal peptides and the C-terminal I and III regions are well conserved, whereas the repetitive domains are highly polymorphic in length and the number of repeat units in the repetitive domain is mainly responsible for the length variation of different LMW-GSs (D'Ovidio et al. 1999; D'Ovidio and Masci 2004).

To investigate the polymorphic LMW-GS complex in bread wheat, one-dimensional SDS-PAGE (Singh et al. 1991; Liu et al. 2010), reversed-phase high-performance liquid chromatography (RP-HPLC; Margiotta et al. 1993) and matrix-assisted laser desorption/ionisation time-offlight (MALDI-TOF; An et al. 2006; Liu et al. 2010) were used. However, their efficiency was hindered by the complex band/peak patterns of LMW-GSs and the overlapping mobility between LMW-GSs and gliadins, particularly when testing allelic variations of LMW-GSs in various wheat varieties (Mamone et al. 2009). Recently, several proteomics studies based on two-dimensional gel electrophoresis (2-DE) and mass spectrometry (MS) were performed to characterise proteins in wheat grain endosperm (Amiour et al. 2002; Andon et al. 2002; Balmer et al. 2006; Ikeda et al. 2006; Dong et al. 2010; Liu et al. 2010). This proteomics-based method was imperfect in identifying the complex members of the LMW-GS gene family because of the high-sequence similarity among different LMW-GSs, the high cost and the strenuous work required. Much attention has been given to allelic variations of LMW-GS proteins, and the genes encoding these proteins have also been well investigated via cDNA and bacterial artificial chromosome (BAC) library screening (Ikeda et al. 2002, 2006; Huang and Cloutier 2008; Dong et al. 2010), providing general elucidation of complex members of the LMW-GS gene family in a particular wheat variety. However, the strategies and technologies (e.g. construction of a DNA or cDNA library) are complex and cannot be widely used to identify LMW-GS genes in a large number of wheat varieties. Meanwhile, molecular markers for LMW-GS genes were investigated to characterise the composition and discriminate the members of the LMW-GS gene family in bread wheat (Long et al. 2005; Ikeda et al. 2006; Zhao et al. 2006, 2007; Huang and Cloutier 2008; Wang et al. 2009, 2010; Dong et al. 2010). These markers might be useful in marker-assisted breeding programmes for the improvement of wheat quality, although using several pairs of primers specific to $>10$ LMW-GS protein alleles was challenging for wheat breeders. Additionally, these molecular markers were all designed based on sequence polymorphisms among the identified LMW-GS haplotypes, and the number of the cloned genes and identified haplotypes are limited. Thus, distinguishing complex members of the LMW-GS gene family in bread wheat using these molecular markers might be difficult.

From the information presented above, elucidating the complex LMW-GS gene family in several bread wheat varieties is demanding due to the lack of a simple and efficient approach to identify the whole gene family. This difficulty has limited the establishment of a clear relationship between LMW-GSs and bread-making quality, and has hindered the use of LMW-GS in wheat quality improvement. In the present study, we developed a marker system comprising conventional polymerase chain reaction (PCR) technology with conserved primers and a high-resolution capillary electrophoresis system. Using the marker system, almost all LMW-GS gene family members could be amplified by conventional PCR and visualised accurately by capillary electrophoresis. Further investigation of LMW-GS genes in the wheat varieties Xiaoyan 54, Chinese Spring, Norin 61 and Glenlea indicated that this marker system could be used on a large scale to accurately discriminate and elucidate the complex members of the LMW-GS gene family in bread wheat.

\section{Materials and methods}

Plant materials

The wheat varieties Xiaoyan 54, Glenlea and Norin 61 were used to validate the conserved primers specific to 
LMW-GS genes in bread wheat. Xiaoyan 54 possessing the LMW-GS alleles Glu-A3d, Glu-B3d and Glu-D3c (Liu 2008 ) is an elite winter Chinese wheat variety with superior bread-making quality. Fourteen unique LMW-GS genes (accession numbers FJ755302-FJ755307 and FJ755309-FJ755316) in Xiaoyan 54 have been characterised with complementary approaches (gene identification through sequencing selected BAC clones, transcript profiling and proteomic analysis; Dong et al. 2010). LMW-GS genes and alleles in Glenlea and Norin 61 had been well understood, i.e. Glu-A3g, Glu-B3g and Glu-D3c in Glenlea, Glu-A3d, Glu-B3i and Glu-D3c in Norin 61 (Ikeda et al. 2002; Huang and Cloutier 2008; Liu et al. 2010). Chinese Spring (Glu-A3a, Glu-B3a and Glu-D3a) and its nulli-tetrasomic lines N1AT1D (nullisomic 1Atetrasomic 1D), N1BT1D and N1DT1B were used to evaluate the efficiency of the conserved primers and to determine the chromosomal locations of the identified LMW-GS genes.

Sequence analysis of LMW-GS genes from Xiaoyan 54 and GenBank

LMW-GS protein sequences (ACY08809-ACY08819) deduced from 11 active genes in Xiaoyan 54 were collected and clustered with ClustalW software (http://www.ebi.ac. uk/Tools/clustalw/index.html) using the default parameters. The phylogenetic tree of 11 LMW-GS in Xiaoyan 54 was constructed using MEGA4.1 (Tamura et al. 2007) with the neighbour-joining method. Bootstrap tests were performed using 1,000 replications.

Thirteen LMW-GS genes (FJ755302-FJ755306 and FJ755309-FJ755316) from Xiaoyan 54, excluding the gene FJ755307 whose coding region was interrupted by a transposon insertion, were clustered using ClustalW. The conserved sequences flanking the repetitive domain were identified and used to design conserved primers specific to LMW-GS genes (Table 1). To optimise the conserved primers, all the other LMW-GS genes with complete coding sequences available in GenBank (http://www. ncbi.nlm.nih.gov/) were retrieved using the keywords "(low glutenin) OR (lmw glutenin) OR (LMW-GS) AND triticum AND complete". The coding sequences of these retrieved LMW-GS genes were clustered using ClustalW. The conserved primers designed above were matched with the clustered sequences. Additionally, to determine whether the designed primers are universal to all known LMW-GS genes, we performed BLAST searches from the EST database using the conserved primers. Based on the results of the analysis, the conserved primers were modified and their loyalty to LMW-GS genes was improved (Table 1). The primers were synthesised using PAGE purification (Invitrogen Biotechnology Co., Ltd.,
Table 1 Three sets of conserved primers designed based on the 13 LMW-GS gene sequences from Xiaoyan 54 BAC clones and those available in GenBank

\begin{tabular}{|c|c|}
\hline Name & Sequences $\left(5^{\prime}-3^{\prime}\right)$ \\
\hline \multicolumn{2}{|l|}{ LMWGS1 } \\
\hline \multicolumn{2}{|l|}{ LMWGS1,2F } \\
\hline LMWGS1,2F $\mathrm{F}^{\mathrm{a}}$ & ATGAAGACCTTCCTCRTCTTTG \\
\hline \multicolumn{2}{|l|}{ LMWGS1R } \\
\hline LMWGS1R-1 & CATGGGTTTAGCTGCTGCA \\
\hline LMWGS1R-2 & CACGGGGTTTAGCTGCTGCA \\
\hline LMWGS1R-3 & CATGGGTTTAGTTGCTGCA \\
\hline LMWGS1R-4 & CATGGGTTCEAGCTGCTGCA \\
\hline \multicolumn{2}{|l|}{ LMWGS2 } \\
\hline \multicolumn{2}{|l|}{ LMWGS1,2F } \\
\hline LMWGS1,2F & ATGAAGACCTTCCTCRTCTTTG \\
\hline \multicolumn{2}{|l|}{ LMWGS2R } \\
\hline LMWGS2R-1 & CAACATTGTTGYTGCATCACAT \\
\hline LMWGS2R-2 & CAACATTGTCGCTGCATCACAT \\
\hline LMWGS2R-3 & CAACATTGTTGCCGGCATCACAT \\
\hline \multicolumn{2}{|l|}{ LMWGS3a } \\
\hline \multicolumn{2}{|l|}{ LMWGS3aF } \\
\hline LMWGS3aF-1 & CCTGGTTTGGAGAAACCATG \\
\hline LMWGS3aF-2 & CCTGGTTTGGAGAGACCATG \\
\hline \multicolumn{2}{|l|}{ LMWGS3aR } \\
\hline LMWGS3aR- $1^{\text {a }}$ & CATYTGYGACCTAGCAAGACG \\
\hline LMWGS3aR- $^{\mathrm{a}}$ & CATCTGCGACCTAGCAAGAT \\
\hline \multicolumn{2}{|l|}{ LMWGS3b } \\
\hline \multicolumn{2}{|l|}{ LMWGS3bF } \\
\hline LMWGS3bF-1 & CCTAGCTTGGAGAAACCATT \\
\hline LMWGS3bF-2 & CCTGGCTTGGAGAAACCATC \\
\hline LMWGS3bF-3 & CCTGGTTTGGAGAGACCATC \\
\hline LMWGS3bF-4 & CCTGGTTTGGAGAAACCATC \\
\hline \multicolumn{2}{|l|}{ LMWGS3bR } \\
\hline 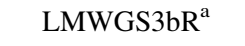 & CATTTGYGACCTAGCAAGACT \\
\hline \multicolumn{2}{|l|}{ LMWGS3c } \\
\hline \multicolumn{2}{|l|}{ LMWGS3cF } \\
\hline LMWGS3cF & GCCGTTGCGCAAATTTCAC \\
\hline \multicolumn{2}{|l|}{ LMWGS3cR } \\
\hline LMWGS3cR ${ }^{\mathrm{a}}$ & CATTTGTGACCTAGCAAGACATC \\
\hline
\end{tabular}

LMWGS1 and LMWGS2 each contains only one pair of primers, and both share the same forward primer, LMWGS1,2F, whereas LMWGS3 comprises three pairs of primers (LMWGS3aF and LMWGS3aR, LMWGS3bF and LMWGS3bR and LMWGS3cF and LMWGS3cR). The primers with unique nucleotides (underlined) were all synthesised and then mixed to work as the forward or reverse primers

a $5^{\prime}$ terminal of the primer was labelled with 6 FAM

Shanghai, China). Additionally, one primer of each pair was labelled with 6-carboxyfluorescein (6-FAM) at the $5^{\prime}$ terminal (Takara Biotechnology Co., Ltd., Dalian, China). 
DNA and RNA isolation and PCR amplification

Genomic DNA was extracted from fresh leaf material collected from 10-day-old wheat seedlings grown in a glasshouse using the cetyl trimethyl ammonium bromide (CTAB) procedure (Saghai-Maroof et al. 1984). Total RNA samples were prepared from developing seeds of Xiaoyan 54 at 14 days post-anthesis using TRIzol ${ }^{\circledR}$ reagent according to the manufacturer's protocol (Invitrogen, Carlsbad, CA) and were converted into cDNAs using Moloney Murine Leukemia Virus Reverse Transcriptase (M-MLV RT; Promega, Madison, WI). PCR was performed in $20-\mu \mathrm{L}$ reaction volumes containing 1.0 U LA Taq DNA polymerase (Takara Bio, Otsu, Japan), $100 \mathrm{ng}$ of genomic DNA, $1 \times$ GC buffer I $\left(\mathrm{Mg}^{2+}\right.$ plus $), 6$ pmol of each PCR primer and $8 \mathrm{nmol}$ of each dNTP. PCR conditions were $95^{\circ} \mathrm{C}$ for $3 \mathrm{~min}$, followed by 35 cycles of $30 \mathrm{~s}$ at $94^{\circ} \mathrm{C}, 30 \mathrm{~s}$ at $59-61^{\circ} \mathrm{C}, 60 \mathrm{~s}$ at $72^{\circ} \mathrm{C}$ and a final extension step of $10 \mathrm{~min}$ at $72^{\circ} \mathrm{C}$. PCR reactions were performed in an ABI 9700 thermal cycler (Applied Biosystems, Foster City, CA).

Analysis of PCR products using the Applied Biosystems 3730 DNA Analyzer

PCR products were diluted 1:30 in water, and $1 \mu \mathrm{L}$ of the diluted products was added to $7 \mu \mathrm{L}$ of $\mathrm{HiDi}$-formamide and $0.1 \mu \mathrm{L}$ of GeneScan 1200 LIZ size standard (Applied Biosystems Foster City, CA). After denaturation at $95^{\circ} \mathrm{C}$ for $10 \mathrm{~min}$, the mixtures were analysed in the Applied Biosystems 3730 DNA Analyzer using the default genotyping module and the G5 dye set. The patterns of the DNA fragments in PCR products were analysed with GeneMapper Software v3.7 according to the manufacturer's instructions.

\section{Cloning and sequencing of DNA fragments}

PCR products were separated on $1.2 \%$ agarose gels and the expected fragments were recovered from the gels with the TIANgel Midi Purification Kit (Tiangen Biotech Co., Ltd., Beijing, China). Purified DNA fragments were ligated into the pGEM-T vector (Promega) and transformed into competent cells of Escherichia coli TOP10 (Tiangen Biotech Co., Ltd.). The positive clones were tested using PCR with the 6FAM-labelled conserved primers, and the size of the PCR fragments was determined using the Applied Biosystems 3730 DNA Analyzer. Clones containing the DNA fragments with the expected sizes were selected and sequenced by SinoGenoMax Co., Ltd. (Beijing, China). Each PCR and sequencing analysis was repeated three to five times to avoid technical errors. Sequence analysis and characterisation were performed using Lasergene software (DNAStar; http://www.dnastar.com/).
Accession numbers

The LMW-GS gene sequences reported in the present study were deposited in GenBank under accession numbers HM640980-HM640985. Specifically, HM640980HM640983 correspond to the four new LMW-GS genes identified in Xiaoyan 54, i.e. LGS2-477, LGS2-590, LGS2655 and LGS2-690, respectively. HM640984 and HM640985 are the two genes cloned from Chinese Spring mentioned below.

\section{Results}

Conservation and length polymorphisms among LMW-GSs in Xiaoyan 54

Xiaoyan 54 is an elite winter wheat variety in China with superior bread-making quality. Fourteen unique LMW-GS genes have been identified through BAC clone screening and sequencing (Dong et al. 2010). The deduced peptides of LMW-GS genes in Xiaoyan 54 have the typical structure of LMW-GS, including a signal peptide, a short $\mathrm{N}$-terminal region, a repetitive domain and $\mathrm{C}$-terminal I, II and III regions (Fig. 1a). Among the 14 identified LMW-GS genes, 11 with an intact open reading frame (ORF) were shown to be expressed by reverse transcription-polymerase chain reaction (RT-PCR), 2-DE and MS (Dong et al. 2010). Multiple alignments of the deduced amino acid sequences were performed using ClustalW software (http://www.ebi.ac.uk/Tools/clustalw/index.html), which revealed that these subunits shared highsequence identity ranging from 62 to $94 \%$ (Fig. 1b). In particular, the signal peptides and the $\mathrm{C}$-terminal $\mathrm{I}$ region were highly conserved. The signal peptide sequences could be summarised as MKTFLI(V)FALL(I)A(I/L)AV (V)AT(A)S(R)AI(V)AQ, and several peptides in the C-terminal I region-LQQLNPCK, FLQQQC, LARSQM and VMQQQCC-were completely conserved in these LMW-GSs (Fig. 1b). In contrast, the repetitive domains were highly polymorphic in length among these LMWGSs, and each LMW-GS has its unique length of repetitive domain, varying from 83 to 192 amino acid residues. The length of the sequences covering the signal peptide, the $\mathrm{N}$-terminal region, the repetitive domain and the partial C-terminal I region $(200,238,150,137,140,134$, 182, 199, 184, 197 and 230 amino acids; Fig. 1b) displayed sufficient polymorphisms among the repetitive domains of these LMW-GSs in Xiaoyan 54. Accordingly, the sequence conservation and length polymorphisms among LMW-GSs in Xiaoyan 54 provided us with the feasibility to distinguish members of the LMW-GS gene family using conventional PCR with conserved primers 
Fig. 1 Sequence alignment of the deduced proteins of 11 active LMW-GS genes in Xiaoyan 54. a Schematic diagram showing the structure of a typical LMW-GS as deduced from their encoding genes. b Multiple alignments of the amino acid sequences deduced from 11 active LMWGS genes in Xiaoyan 54 (Dong et al. 2010). The s- and m-type subunits, with serine and methionine as the first amino acids of the mature LMW-GS (ACY08809, ACY08812ACY08819), contain a signal peptide (Sig), an N-terminal domain (N-ter), a repetitive domain (Rep) and a C-terminal domain (C-ter), which is further divided into three regions: $\mathrm{C}$-terminal I (C-ter I), C-terminal II (C-ter II) and C-terminal III (C-ter III). The two i-type subunits (ACY08810 and ACY08811) lack the N-terminal domain (enclosed with broken lines), starting directly with the repetitive domain after the signal peptide. The group of numbers $(200,238,150,137$, 140, 134, 182, 199, 184, 197 and 230) represents the length of the sequences covering the signal peptide, the $\mathrm{N}$-terminal domain, the repetitive domain and part of the C-terminal I region

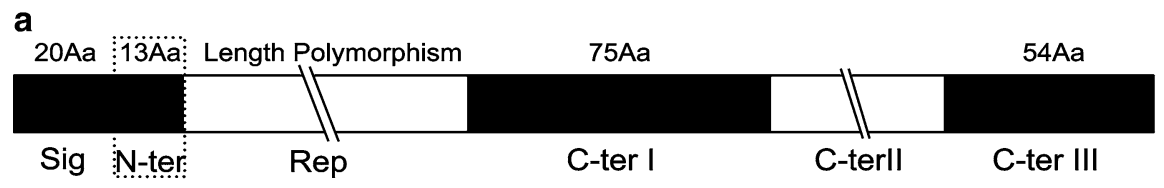



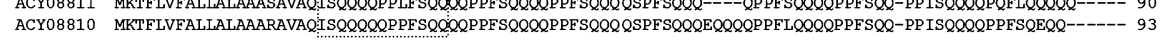

ACY08819 QQ-------PSFSQQQQPPFSQQQ--------PPFSQQQQPVIPQQPSFSQQQLPPFSQQQPPFSQQ-----------------QQPVLPQQ------------- 152

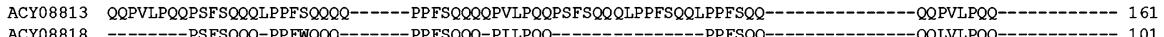
ACY08818 ---------PSFSQQQ-PPFWQQQ--------PPFSQQQ-PILPQQ----------------PPFSQQ-----------------QQLVLPQQ------------- 101

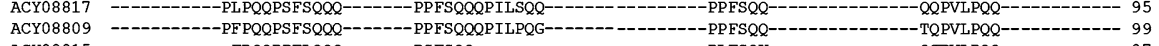
ACY08815 ------------FPQQPPFLQQQ-------PSFSQQ-------------------PLFSQK-------------- QLPVLPQQ----------- 87

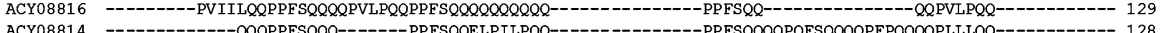
ACY08814



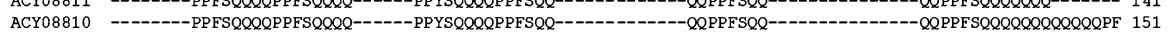

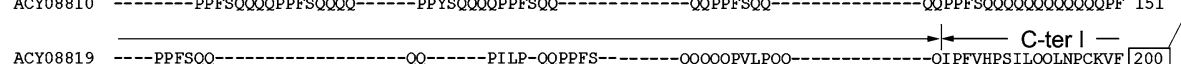
ACY08813 ----PPFSQQQLPPFSQQLPPFSQQ----QQ------PVLP-QOPPFS--------QQQQQPILPQQPPFSQQQQPVLLQQQIPFVHPSILQQLNPCKVF 238 ACY08818 ----PPFSQQ--------------------QQ-------PVLPPQQSPFP--------QQQQHQQLVQQ--------------QI PVVQPSILQQLNPCKLF 150 ACY08817 ----SPFSQQ--------------------QQ-------LVLP----------------PQQQQQQLVQQ---------------QI PIVQPSVLQQLNPCKVF 137

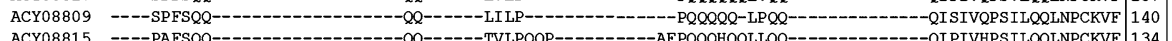
ACY08815 -----PAFSQQ---------------------QQ-------TVLPQQP-----------AF PQQQHQQLLQQ----------------QI PIVHPS ILQQLNNPCKVF 134

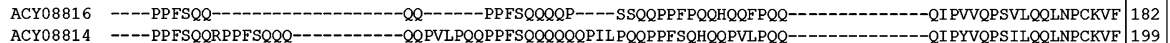
ACY08812 ----PPFSQQQPPFSQQQ------------QQ-------PPFSQQQQQ-PI LLQQPPFSQHQQPVLPQQ---------------QI PSVQPS ILQQLNPCKVF 184 ACY08811 ----PPFTQQ--------------QQPPFSQQPPISQQQQP--------PF SQQQQPPF SQQ------------QQIPVIHPSVLQQLNPCKVF 197 ACY08810 TQQQPPFSQQPPISQQQQQQQQQQQPFTQQQPPFSQQPPISQQQQP--------PF SQQQQTPFSQQ------------QQIPVIHPSVLQQLNPCKVF 230 ACY08819 LQQQCSPVAMPQSLARSQMLQQSSCHVMQQQCCQQLLPQIPQQSRYEAIRAI IYSIILQEQQQ--------VQGSIQSQQQQPQQLGQCVSQPQQQSQQQ-- 291 ACY08813 LQQQCSPVAMPQSLARS QMLQQSSCHVMQQQCCQQLPQIPQQSRYEAIRAIVYSIILQEQQQ--------VQGS IQTQQQQPQQLGQCVSQPQQQSQQQ-- 329 ACY08818 LQQQCSPVAMPQRLARSQMLQQSSCHVMQQQCCQQLPQI PQQSRYEAIRAI IYSIILQEQQQ-------VQGS IQSQQQQPQQLGQCVSQPQQQSQQQ-- 241 ACY08817 LQQQCSPVAMPQRLARSQMWQQSSCHVMQQQCC QQLQQIPEQSRYEAIRAI----ILQEQQ---------QGFVQPQQQQPQQSGQGVSQSQQQSQQQ-- 222 ACY08809 LQQQCSPVVMPQRLARSQMWQQSSCHVMQQQCCQQLSQIPEQSRYDAIRAITYPIILQEQQ---------QGFVQAQQQQPQQSGQGVSQSQQQSQQQ-- 229 ACY08815 LQQQCSPVAMPQHLARSQMWQQSSCNVMQQQCCQQLPRIPEQSRYEAIRAIIFSIILQEQQ---------QGFVQPQQQQPQQSVQGVYQPQQQSQQQ-- 223 ACY08816 LQQQCSHVAMSQRLARSQMWQQSSCHVMQQQCCQQLPQIPEQSRSEAIRAIVYSIILQEQQ----------QGFVQPQQQQPQQSGQGVSQHQQQSQQQQQ 273 ACY08814 LQQQCSPVAMPQSLARSQMLWQSSCHVMQQQCCQQLPRIPEQSRYDAIRAIIYS IVLQEQQH--------GQGFNQPQQQQPQQSVQGVSQPQQQ-QKQ-- 289 ACY08812 LQQQCSPVAMPQSLARSQMLWQSSCHVMQQQCCRQLPQIPEQSRYDAIRAI IYSIVLQEQQH-------GQGLNQPQQQQPQQSVQGVSQPQQQ-QKQ-- 274 $\begin{array}{ll}\text { ACY08811 } & \text { LQQQCIPVAMQRCLARSQMLQQSICHVMQQQCCQQLRQIPEQSRHESIRAIVYSIILQQQQQQQQQQQQRQS I IQYQQQQPQQLGQCVSQPQQQLQQQ-- } 295 \\ \text { ACY08810 } & \text { LQQQCIPVAMQRCLARSQMLQQSICHVMQQQCCQQLRQIPEQSRHESIRAIVYSIILQQQQQQQQQQ-GQSI IQYQQQQPQQLGQCVSQPQQQLQQQ-- } 327\end{array}$

ACY08819 ACY08813 ------------LGQOPQQQ---QLAHGTFLQPHQIAQLEVMTS IALRTLPTMCNVNVPL YRTTTRVPFGVGTGVGGY 392 ACY08818 --------------LGQQPQQQ--QLAQGTFLQPHQIAQLEVMTSIALRILPTMCSVNVPLYRTTTSVPFDVGTGVGAY 304 ACY08817 LGQCSFQQPQ--QQLGQQPQQQQQQVLQGTFLQPHQIAHLEAVTSIALRTLPTMCSVNVPLYSATTSVPFGVGTGVGAY 299 ACY08809 LGQCSFQQPQ--QQLGQQPQQQ--QVQQGTFLQPHOIAHLEVMTSIALRTLPTMCSVNVPLYSSTTSVPFGVGTGVGAY 304 ACY08815 LGQCSFOOPQ--OOLGOOPOOQ--QVQKGTFLQPHQIARLEVMTSIALRTLPTMCSVNVPLYSSITSAPLGVGSRVGAY 298 ACY08816 LGQCSFQQPQQLQOLGQOPQQQ--QI PQGIFLOPHOISOLEVMTSIALRTLPTMCGVNVPLYSSTTIMPFSIGTGVGGY 350 ACY08814 LGQCSFORPOQ-OOLGOWPQOQ--OVPOGTLLOPHOIAOLELIMTSIALRTLPMMCSVNVPVYGTTTSVPFGVGTVGAY 365 ACY08812

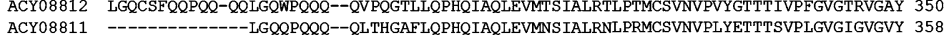
ACY08810 -----------LGQQPQQQ--QLAHGTFLQPHQIAQLEVMTSIALHNLPMMCSVNVPLYETTTSVPLGIGIGVGVY 390 that were matched with the conserved regions flanking the repetitive domains.

Development of conserved primers for identifying LMW-GS genes in bread wheat

To design conserved primers, we aligned the coding sequences of the 13 unique LMW-GS genes with complete coding sequences identified in Xiaoyan 54, excluding the LMW-GS gene (FJ755307) interrupted with a transposon insertion (Dong et al. 2010). The sequence alignment revealed that the sequences encoding the signal peptide and C-terminal I region shared high identity, up to $90 \%$. Thus, the conserved nucleotide sequences were used for the primer design (Fig. 2). To ensure the reproducibility and reliability of the analysis, three sets of conserved primers that matched with different conserved regions-LMWGS1, LMWGS2 and LMWGS3 - were developed (Fig. 2; Table 1). LMWGS1 and LMWGS2 each contained only one pair of primers, whereas LMWGS3 comprised three pairs of primers (LMWGS3aF and LMWGS3aR, LMWGS3bF and LMWGS3bR and LMWGS3cF and LMWGS3cR; Fig. 2). LMWGS1 and LMWGS2 were designed based on the high-sequence identity of the coding sequences for the signal peptide and C-terminal I region. They shared the same forward primer, LMWGS1,2F, located in the coding region for the signal peptides and starting from the initiation codon of the LMW-GS genes, while their reverse primers, LMWGS1R and LMWGS2R, were located in different regions of C-terminal I (Fig. 2). 


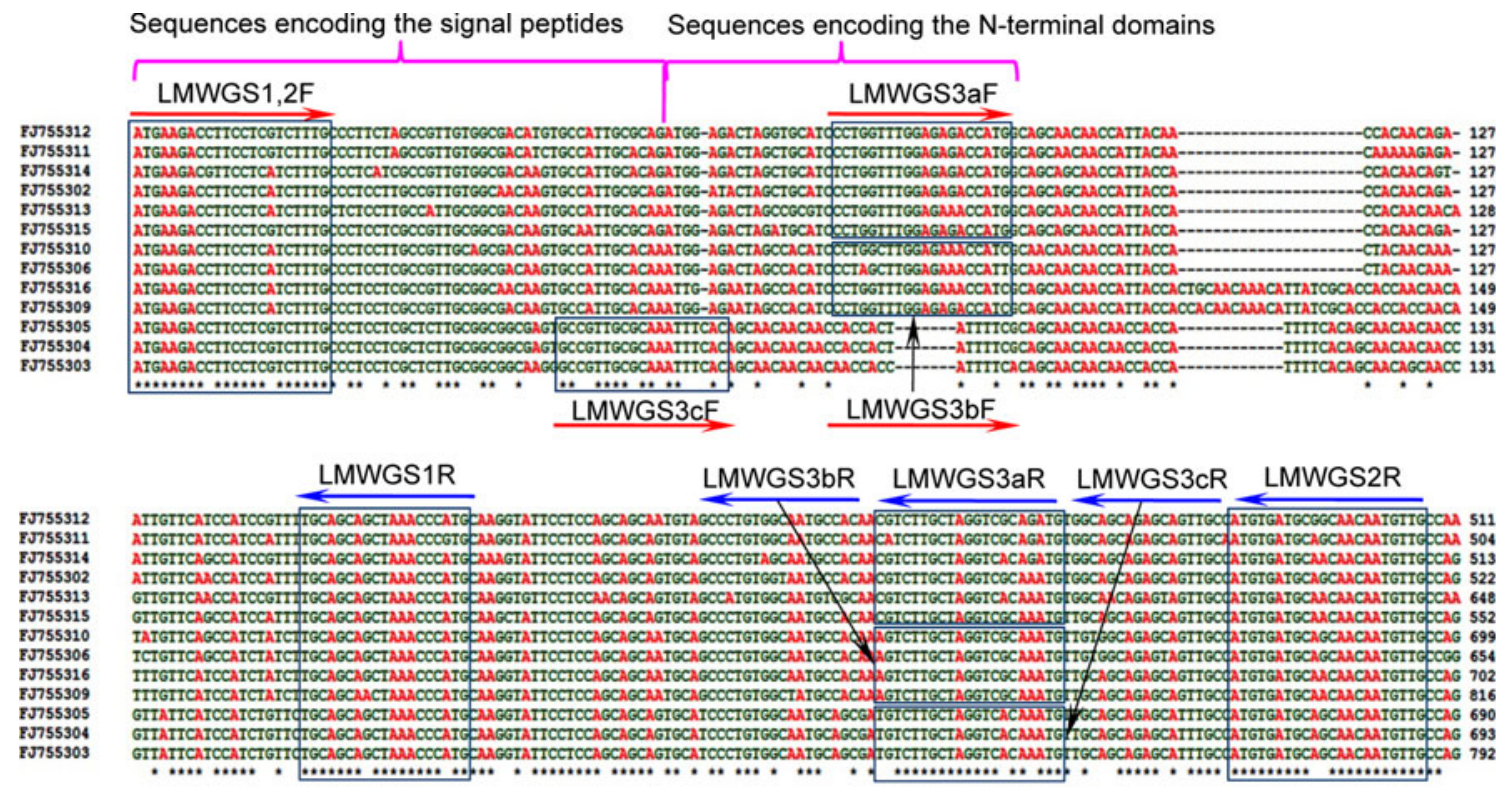

Sequences encoding the $\mathrm{C}$-terminal I regions

Fig. 2 Design of the conserved primers based on nucleotide sequence conservation of the LMW-GS genes in Xiaoyan 54. Based on the conserved sequences of LMW-GS genes, three sets of conserved primers were designed: LMWGS1, LMWGS2 and LMWGS3. LMWGS1 comprised LMWGS1,2F and LMWGS1R. LMWGS2 contained the pair of primers LMWGS1,2F and LMWGS2R, whereas LMWGS3 comprised the three pairs of conserved primers LMWGS3a

The different locations of the primers resulted in a 108-bp longer amplicon of LMW-GS2 than that of LMW-GS1 for each LMW-GS gene. Theoretically, all the LMW-GS genes could be amplified simultaneously by conventional PCR using each set of the conserved primers: i.e. $>10$ amplicons might be obtained with LMWGS1 or LMWGS2. To simplify the PCR amplification, a third set of primers, LMWGS3, was designed that contained three pairs of primers specific to a subset of LMW-GS genes. The sequence alignment of the subunits deduced from 11 active LMW-GS genes in Xiaoyan 54 revealed that these LMWGSs can be categorised into four groups (I, II, III and IV; Supplementary Fig. 1). Accordingly, three pairs of conserved primers were designed. LMWGS3a was specific to groups I and II, LMWGS3b to group III and LMWGS3c to group IV. Primers LMWGS3aF and LMWGS3bF were derived from the N-terminal coding region, while LMWGS3cF was designed based on the unique coding region for the signal peptide and the repetitive region of LMW-i types. The reverse primers with unique nucleotides-LMWGS3aR, LMWGS3bR and LMWGS3cRwere positioned at the same coding region for the $\mathrm{C}$-terminal I region (Fig. 2). Thus, each of these group-specific primers could amplify a subset of LMW-GS genes, and all three subsets of amplified genes would comprise the entire LMW-GS gene family in a bread wheat variety.
(LMWGS3aF and LMWGS3aR), LMWGS3b (LMWGS3bF and LMWGS3bR) and LMWGS3c (LMWGS3cF and LMWGS3cR). All of the conserved primers were matched to the sequences flanking the repetitive sequences. Specifically, all the forward primers were located in the sequences encoding the signal peptide or the $\mathrm{N}$-terminal domain, while the reverse primers were located in the sequences encoding the C-terminal I region

To optimise the conserved primers, the LMW-GS gene sequences deposited in GenBank were used to explore the conservation of these primers designed from LMW-GS genes in Xiaoyan 54. The database was searched with the keywords "(low glutenin) OR (lmw glutenin) OR (LMWGS) AND triticum AND complete", and 384 LMW-GS genes with complete coding sequences were retrieved, including eight LMW-GS genes in seven BAC sequences. The coding sequences of these LMW-GS genes were used for cluster analysis using ClustalW. Three sets of conserved primers, designed according to LMW-GS genes in Xiaoyan 54 , were matched with counterpart clustered nucleotide sequences, which were slightly modified, if necessary. Additionally, dbEST of GenBank was searched by BLAST with the improved primers. Based on the analysis of BLAST hits, the conserved primers were modified and made specific to all known LMW-GS genes. These modifications improved the representativeness of the conserved primers, and the improved primers matched $>85 \%$ of the LMW-GS gene sequences deposited in GenBank.

\section{Validation of the conserved primers in Xiaoyan 54}

Based on the conserved sequences and length polymorphisms among LMW-GS genes in Xiaoyan 54 and those available in GenBank, three sets of conserved primers 
Fig. 3 Analysis of polymerase chain reaction (PCR) products amplified from Xiaoyan 54 with the conserved primers. a Electrophoresis of the PCR products amplified from Xiaoyan 54 with the conserved primers in an agarose gel. $M$ DNA ladder Marker III (200, 500, 800, 1,200, 2,000, 3,000 and 4,500 bp; Tiangen Biotech Co., Ltd.). b Electropherograms showing capillary

electrophoresis separation of the DNA fragments amplified from Xiaoyan 54 with the conserved primers. The horizontal axis shows the size of the detected DNA fragments, while the vertical axis displays the intensity of the signal (i.e. the concentration of DNA fragments in the PCR products). The orange peaks match the standard DNA fragments in the GeneScan 1200 LIZ size standard, while the blue ones representing the DNA fragments in the PCR products, should match theoretically with the LMW-GS genes in Xiaoyan 54. The numbers on the horizontal axis represent the size of the corresponding peak in the GeneScan 1200 LIZ size standard (orange). In Xiaoyan 54, 14 blue peaks (DNA fragments) could be detected with the conserved primer LMWGS1, 16 with LMWGS2 and 16 with LMWGS3 (7 with LMWGS3a, 6 with LMWGS3b and 3 with LMWGS3c). The data shown are representative of four independent sets of PCR amplifications and DNA fragment analyses a

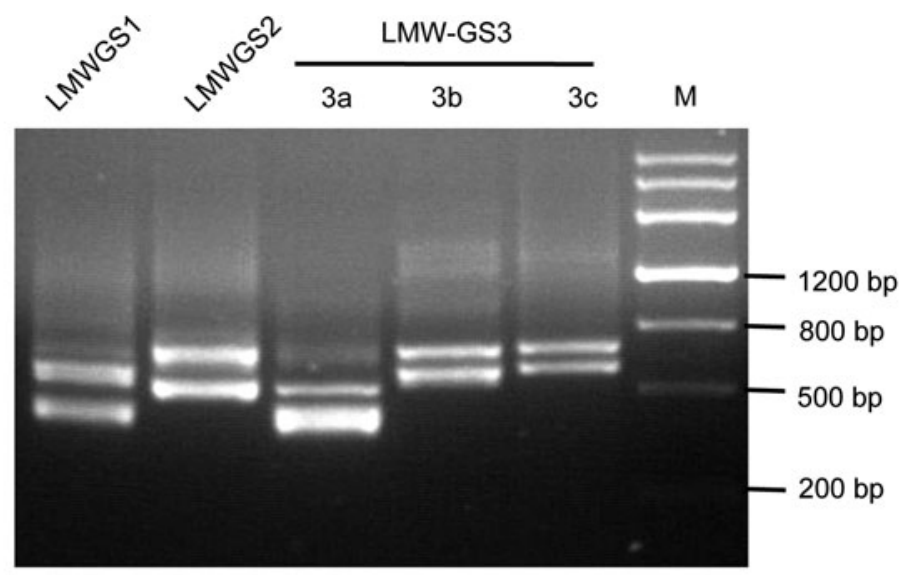

b

b

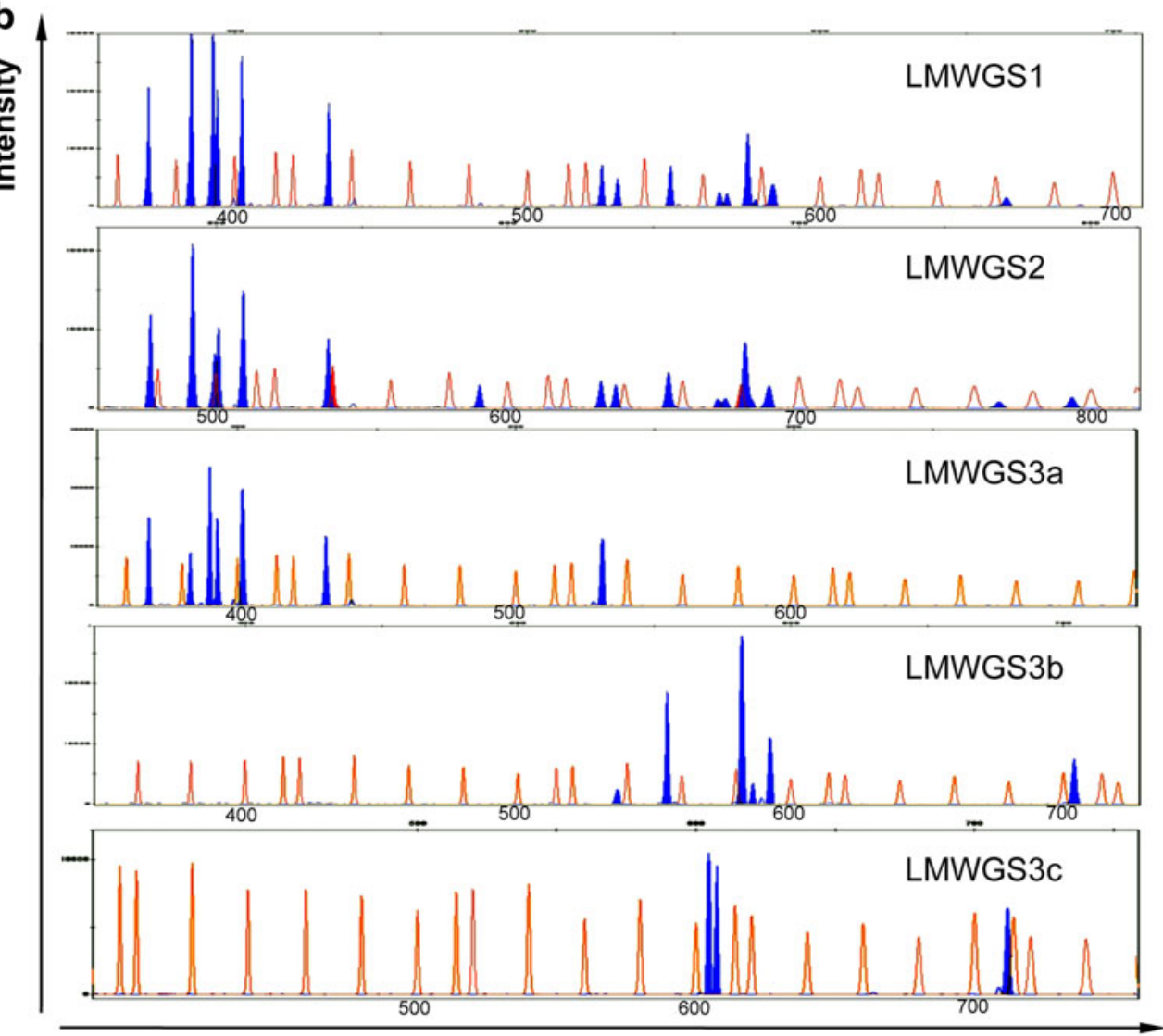

Size

flanking the repetitive domain were designed. To ensure the efficiency of these primers in characterising LMW-GS genes in bread wheat, Xiaoyan 54 was analysed. Only two main bands for each pair of primers were detected in the PCR products using $1.5 \%$ agarose gel electrophoresis (Fig. 3a). To effectively and clearly display all the DNA fragments in the PCR products, capillary electrophoresis was applied to DNA fragment analysis, resulting in a high resolution (up to $1 \mathrm{bp}$; Butler et al. 2004). The electropherograms revealed that 15 DNA fragments (blue peaks) were detected in the PCR products with the primer LMWGS1, 16 DNA fragments with LMWGS2, 7 DNA fragments with LMWGS3a, 6 DNA fragments with LMWGS3b and 3 DNA fragments with LMWGS3c (Fig. 3b). These data suggested that 15 or 16 DNA fragments could be amplified from Xiaoyan 54 using conventional PCR with one set of the conserved primers, consistent with the previous observation that 14 unique LMW-GS genes were identified in Xiaoyan 54. Thus, the conserved primers and high-resolution capillary electrophoresis comprised a new molecular marker system for simple and efficient characterisation of the composition of LMW-GS genes in a bread wheat variety. 
Table 2 Size of the DNA fragments amplified from Xiaoyan 54 with three sets of conserved primers and subsequently detected with the Applied Biosystems 3730 DNA Analyzer

\begin{tabular}{|c|c|c|c|c|c|c|c|c|c|c|c|c|}
\hline \multirow[t]{2}{*}{ Gene } & \multicolumn{2}{|c|}{ LMWGS1 } & \multicolumn{2}{|c|}{ LMWGS2 } & \multicolumn{2}{|c|}{ LMWGS3a } & \multicolumn{2}{|c|}{ LMWGS3b } & \multicolumn{2}{|c|}{ LMWGS3c } & \multirow[t]{2}{*}{ Accession no. ${ }^{c}$} & \multirow[t]{2}{*}{ Identity ${ }^{\mathrm{d}}(\%)$} \\
\hline & Theo $^{\mathrm{a}}$ & $\operatorname{Exp}^{b}$ & Theo & $\overline{\operatorname{Exp}}$ & Theo & $\operatorname{Exp}$ & Theo & $\operatorname{Exp}$ & Theo & Exp & & \\
\hline$L G S 2-477^{\mathrm{e}, \mathrm{f}}$ & 377 & 370 & 485 & 477 & 366 & 368 & - & - & - & - & AJ519836 & 98 \\
\hline D3-4 & 392 & 385 & 500 & 492 & 381 & 383 & - & - & - & - & FJ755311 & 100 \\
\hline$D 3-5^{\mathrm{f}}$ & 399 & 393 & 507 & 499 & 388 & 390 & - & - & - & - & FJ755312 & 100 \\
\hline D3-7 & 401 & 394 & 509 & 501 & 390 & 393 & - & - & - & - & FJ755314 & 100 \\
\hline$A 3-1$ & 410 & 402 & 518 & 509 & 399 & 402 & - & - & - & - & FJ755302 & 100 \\
\hline D3-2 & 440 & 432 & 548 & 538 & 429 & 432 & - & - & - & - & FJ755315 & 100 \\
\hline$L G S 2-590^{\mathrm{e}, \mathrm{f}}$ & 493 & $\mathrm{~N}^{\mathrm{g}}$ & 601 & 590 & - & - & - & - & 512 & $\mathrm{~N}$ & FJ549941 & 99 \\
\hline D3-6 & 536 & 525 & 644 & 632 & 525 & 531 & - & - & - & - & FJ755313 & 100 \\
\hline$B 3-1$ & 542 & 530 & 650 & 637 & - & - & 531 & 537 & - & - & FJ755306 & 100 \\
\hline$L G S 2-655^{\mathrm{e}, \mathrm{f}}$ & 561 & 549 & 669 & 655 & - & - & 550 & 556 & - & - & EU369731^6 & 100 \\
\hline$A 3-3^{\mathrm{f}}$ & 578 & 566 & 686 & 672 & - & - & - & - & 597 & 605 & FJ755305 & 100 \\
\hline$A 3-2$ & 581 & 568 & 689 & 675 & - & - & - & - & 600 & 608 & FJ755304 & 100 \\
\hline D3-1 & 587 & 575 & 695 & 682 & - & - & 576 & 583 & - & - & FJ755310 & 100 \\
\hline D3-3 & 590 & $\mathrm{~N}$ & 698 & $\mathrm{~N}$ & - & - & 579 & 586 & - & - & FJ755316 & 100 \\
\hline$L G S 2-690^{\mathrm{e}, \mathrm{f}}$ & 596 & 584 & 704 & 690 & - & - & 585 & 593 & - & - & AY585349 & 97 \\
\hline$A 3-4$ & 680 & 664 & 788 & 768 & - & - & - & - & 699 & 715 & FJ755303 & 100 \\
\hline$B 3-2$ & 704 & 688 & 812 & 792 & - & - & 693 & 707 & - & - & FJ755309 & 100 \\
\hline$B 3-3^{\mathrm{f}}$ & $-{ }^{\mathrm{h}}$ & - & - & - & - & - & - & - & - & - & FJ755307 & - \\
\hline
\end{tabular}

a Theoretical size of DNA fragments

b Experimental size of DNA fragments

c FJ755302-FJ755307 and FJ755309-FJ755316 were identified in Xiaoyan 54 BAC clones reported by Dong et al. (2010)

${ }^{d}$ Nucleotide sequence identity of the DNA fragments to previously reported LMW-GS genes

e The new genes from Xiaoyan 54 identified in the present study

${ }^{\mathrm{f}}$ The genes were not expressed in the developing seeds of Xiaoyan 54

g Not detected

h Not applicable

To check the consistency of the DNA fragments revealed by the new marker system with the LMW-GS genes previously identified in Xiaoyan 54 BAC clones, the experimental size of the DNA fragments was calculated with the GeneScan 1200 LIZ size standard using GeneMapper Software v3.7. Next, the experimental size of the DNA fragments and the theoretical size of 13 genes with complete sequences in Xiaoyan 54 [excluding the LMW-GS gene (FJ755307) interrupted with a transposon insertion] were compared (Table 2). The experimental size of the amplicons of LMW-GS1 ranged from 370 to $688 \mathrm{bp}$, and that of LMW-GS2 from 477 to $792 \mathrm{bp}$ (Table 2). The experimental size differences between the amplicons of both primers were 104-107 bp, which was consistent with the theoretical difference of $108 \mathrm{bp}$. The third conserved primer set, LMWGS3, comprised three pairs of primers (LMWGS3a, LMWGS3b and LMWGS3c), and each could amplify an independent but complementary subset of LMW-GS genes in a given bread wheat variety (Table 2). Thus, 16 unique DNA fragments in Xiaoyan 54 were identified with the third primer set, which was consistent with the data from LMWGS1 and LMWGS2 (Table 2). The integrated data from the three sets of conserved primers demonstrated that 17 DNA fragments can be identified from Xiaoyan 54 (Table 2). Except for four new DNA fragments, the other 13 fragments were well matched with the LMW-GS genes isolated in Xiaoyan 54, although small deviations existed between the experimental size and theoretical sizes (Table 2). These kinds of deviations have been reported to be universal and were probably caused by the capillary electrophoresis and the internal standard system (GeneScan 1200 LIZ size standard; Rosenblum et al. 1997; Akbari et al. 2008). Additionally, to investigate whether all the DNA fragments were derived from LMW-GS genes, the 17 DNA fragments were cloned, sequenced and aligned with LMW-GS genes. In total, 13 DNA fragments that were matched in size with the LMW-GS genes in Xiaoyan 54 were identical to the corresponding LMW-GS genes (Dong et al. 2010), and 4 new DNA fragments were 
identified with $>97 \%$ identity to the LMW-GS genes in GenBank by BLAST searches (Table 2). The four LMWGS newly identified genes in Xiaoyan 54, corresponding to DNA fragments 477, 590, 655 and 690 (size of amplicons from primer LMWGS2), were named LGS2477, LGS2-590, LGS2-655 and LGS2-690, respectively (Table 2). These genes may all be pseudogenes because stop codons were present in their coding regions. Collectively, using this new marker system, 17 unique LMWGS genes could be detected in Xiaoyan 54, and only one, B3-3 (FJ755307) reported by Dong et al. (2010), could not be detected because it was interrupted by a large transposon insertion. These findings suggest that $>18$ unique LMW-GS genes exist in the bread wheat variety Xiaoyan 54 (Table 2).

To validate our new marker system, the transcription profiles of LMW-GS genes in developing seeds of Xiaoyan 54 were also investigated. RT-PCR analysis using total RNA extracted from developing seeds of Xiaoyan 54 and the electropherogram displaying 11 blue peaks indicated that 11 unique genes were expressed (Supplementary Fig. 2; Table 2). These expressed genes matched exactly with the 11 active genes $(A 3-1, A 3-2, A 3-4, B 3-1, B 3-2$, $D 3-1, D 3-2, D 3-3, D 3-4, D 3-6$ and D3-7) observed by Dong et al. (2010) previously.

These results of the analysis of LMW-GS genes in Xiaoyan 54 at the DNA and cDNA levels demonstrated that this new marker system, comprising conventional PCR with conserved primers and high-resolution capillary electrophoresis, could be used to effectively discriminate the LMW-GS genes of the complex gene family in Xiaoyan 54, and might be universally applied to identify LMWGS genes in bread wheat.

\section{Characterisation of the LMW-GS genes in Chinese Spring with the marker system}

The efficiency of the marker system in characterising LMW-GS genes was evaluated in another bread wheat variety, Chinese Spring. Conventional PCR was performed with the genomic DNA of Chinese Spring using these conserved primers, and DNA fragments in the PCR products were identified using the Applied Biosystems 3730 DNA Analyzer. The data showed that $>10$ DNA fragments could be displayed in the PCR products amplified with each set of conserved primers. Specifically, 15 DNA fragments were identified with the primer LMWGS1, 14 with LMWGS2, 7 with LMWGS3a, 7 with LMWGS3b and 2 with LMWGS3c (Fig. 4a). With the help of the GeneScan 1200 LIZ size standard, the experimental size of the DNA fragments was calculated and compared (Supplementary Table 1), revealing that most of the DNA fragments in each PCR product matched well with each other.
The only exception was DNA fragment 537, which could only be detected in the PCR products with the primer LMWGS3c (Supplementary Table 1; Fig. 4a). To confirm whether it belonged to the LMW-GS gene family, fragment 537 was cloned and sequenced. Using the sequence of fragment 537 (HM640984), BLAST searches revealed that its corresponding gene might encode a LMW-i-type subunit. With the new marker system, we identified $\geq 16$ DNA fragments in Chinese Spring representing 16 LMW-GS genes.

Typical LMW-GS genes are located at the Glu-A3, Glu$B 3$ and $G l u-D 3$ loci on the short arms of chromosome $1 A$, $1 B$ and $1 D$, respectively (Singh and Shepherd 1988; D'Ovidio and Masci 2004). To determine the chromosomal locations of individual LMW-GS genes, three Chinese Spring nulli-tetrasomic lines-N1AT1D, N1BT1D and N1DT1B-were used. Conventional PCR was performed with three sets of conserved primers in the marker system, and the PCR products were displayed using the Applied Biosystems 3730 DNA Analyzer, followed by analysis using GeneMapper Software v3.7. Compared to the fragments detected in Chinese Spring, four, four and seven distinct DNA fragments were missing in the nulli-tetrasomic lines N1AT1D, N1BT1D and N1DT1B, respectively (Fig. 4b; Table 3), suggesting that four LMW-GS genes were located on chromosome $1 A$, four on $1 B$ and seven on 1D. Unexpectedly, DNA fragment 684 could be detected in all three Chinese Spring nulli-tetrasomic lines (Fig. 4b; Table 3), although this fragment corresponding to the D3-3 gene in Xiaoyan 54 was mapped to the Glu-D3 locus (Dong et al. 2010; Table 2). This inconsistency suggested that some other sequences might be amplified or another LMW-GS gene with the same DNA fragment size might be located at loci other than $G l u-D 3$. To investigate its origins, DNA fragment 684 was cloned and sequenced, and two sequences were obtained. One was identical to D3-3 (Dong et al. 2010) and the other was homologous to a LMW-GS pseudogene (EU057598) with 99\% identity by online BLAST. Further analysis revealed that this new LMW-GS gene (HM640985) was located on chromosome $1 B$ for its absence in N1BT1D. Collectively, using the developed marker system, 17 LMW-GS genes in Chinese Spring, represented by the DNA fragments, were shown to be located on the group 1 chromosomes, with 4 on chromosome $1 A, 5$ on $1 B$ and 8 on $1 D$.

\section{Discussion}

Previously, several molecular markers were developed based on sequence polymorphisms among LMW-GS genes in bread wheat (Zhang et al. 2004; Long et al. 2005; Ikeda et al. 2006; Zhao et al. 2006, 2007; Wang et al. 2009, 2010). 
Fig. 4 Electropherograms displaying the patterns of the DNA fragments detected in Chinese Spring and its nullitetrasomic lines with the marker system. a Identification of the LMW-GS genes in Chinese Spring with the developed marker system. b Determination of the location of the DNA fragments with the Chinese Spring nulli-tetrasomic lines N1AT1D, N1BT1D and N1DT1B. The horizontal and vertical axes are the same as those described in Fig. 3b. In Chinese Spring, 15 blue peaks (DNA fragments) could be detected with the conserved primer LMWGS1, 14 with LMWGS2 and 16 with LMWGS3 (7 with LMWGS3a, 7 with LMWGS3b and 2 with LMWGS3c). The data collected from three sets of conserved primers indicated that 12 blue peaks (DNA fragments) were detected in N1AT1D, 12 in N1BT1D and 9 in N1DT1B. However, DNA fragment 684 (marked with red arrows) could be detected in all three nullitetrasomic lines. All data provided are representative of four independent sets of PCR amplifications and analyses using the Applied Biosystems 3730 DNA Analyzer
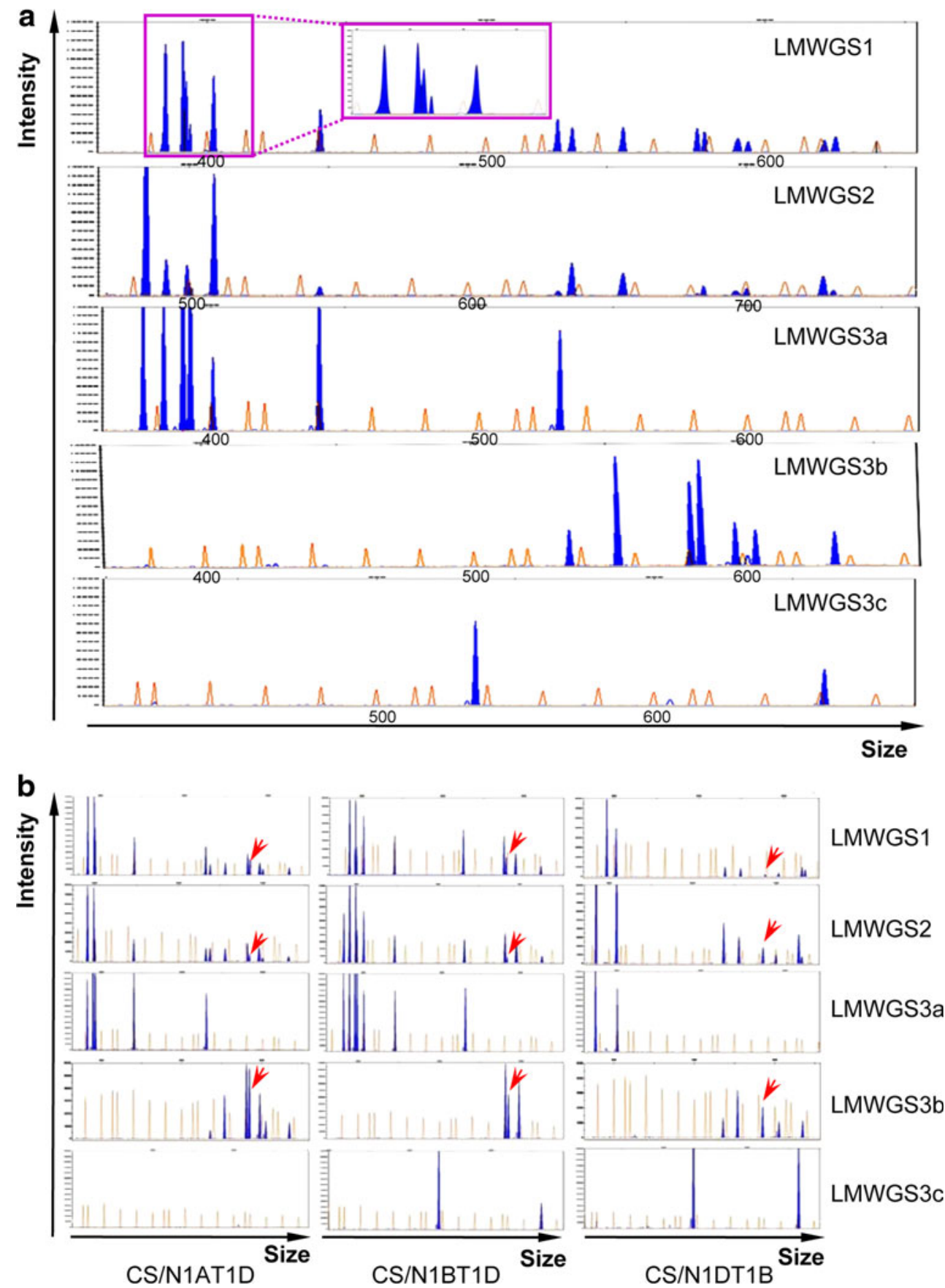

Here, we focussed on the conserved structure and length polymorphisms among LMW-GS genes. Comprising conserved primers and capillary electrophoresis, a new marker system was developed to characterise multiple LMW-GS genes in bread wheat varieties. This system was validated in Xiaoyan 54 and Chinese Spring, confirming that it could be efficiently used for large-scale characterisation of the complex LMW-GS gene family in bread wheat.

The new marker system, comprising conserved primers and capillary electrophoresis, is useful to elucidate the complex members of the LMW-GS gene family
Although several hundred LMW-GS genes have been cloned and deposited in GenBank, accurate characterisation of the complex members of the LMW-GS gene family in a bread wheat variety is still difficult regarding wheat quality improvement (Ikeda et al. 2002; Huang and Cloutier 2008; Dong et al. 2010). In the present study, we focussed on sequence conservation and length polymorphisms of LMW-GS genes and established a new marker system with which all LMW-GS genes could be characterised using conventional PCR. Previously, LMW-GS genes in three bread wheat varieties-Norin 61, Glenlea 
Table 3 DNA fragments amplified from Chinese Spring and its nulli-tetrasomic lines N1AT1D, N1BT1D and N1DT1B

\begin{tabular}{|c|c|c|c|c|c|}
\hline Chromosome & Chinese Spring & N1AT1D & NIBT1D & N1DT1B & Accession no. ${ }^{\mathrm{a}}$ \\
\hline $1 A$ & $485^{\mathrm{b}}$ & $\mathrm{N}^{\mathrm{c}}$ & 485 & 485 & $-^{\mathrm{d}}$ \\
\hline $1 D$ & 492 & 492 & 492 & $\mathrm{~N}$ & AK $330800^{\mathrm{e}}$ \\
\hline $1 D$ & 499 & 499 & 499 & $\mathrm{~N}$ & - \\
\hline $1 D$ & 501 & 501 & 501 & $\mathrm{~N}$ & $D Q 457417^{\mathrm{f}}$ \\
\hline $1 A$ & 509 & $\mathrm{~N}$ & 509 & 509 & - \\
\hline $1 D$ & 547 & 547 & 547 & $\mathrm{~N}$ & FH615311 \\
\hline $1 A$ & 596 & $\mathrm{~N}$ & 596 & 596 & - \\
\hline $1 D$ & 632 & 632 & 632 & $\mathrm{~N}$ & DQ357052/AY214450 \\
\hline $1 B$ & 637 & 637 & $\mathrm{~N}$ & 637 & X84960 \\
\hline $1 B$ & 655 & 655 & $\mathrm{~N}$ & 655 & - \\
\hline $1 D$ & 682 & 682 & 682 & $\mathrm{~N}$ & X84961 \\
\hline $1 B / 1 D$ & 684 & 684 & 684 & 684 & DQ357057(1D) \\
\hline $1 D$ & 695 & 695 & 695 & $\mathrm{~N}$ & - \\
\hline $1 B$ & 700 & 700 & $\mathrm{~N}$ & 700 & - \\
\hline $1 A$ & 725 & $\mathrm{~N}$ & 725 & 725 & AT453154/FJ876821 \\
\hline $1 B$ & 729 & 729 & $\mathrm{~N}$ & 729 & - \\
\hline
\end{tabular}

a The LMW-GS genes/alleles, identified from Chinese Spring reported in GenBank, share the same size and/or high identity with the DNA fragments detected in the present study

b Sizes of the DNA fragments were represented with the data from the primer LMWGS2

c Not detected

d Not applicable

e From the cDNA clone in Chinese Spring, which was not annotated to be a LMW-GS gene

${ }^{\mathrm{f}}$ Having high-sequence identity with the sequences of the corresponding DNA fragment, but containing some deletions in the repetitive region

and Xiaoyan 54-were extensively investigated using complementary approaches, and $>10$ genes had been identified in each variety (Ikeda et al. 2002; Huang and Cloutier 2008; Dong et al. 2010). Thus, the data from these three varieties would be useful to validate the efficiency of our marker system. In Xiaoyan 54, using three sets of conserved primers in our marker system, 17 DNA fragments were detected, sequenced and confirmed to be LMW-GS genes, of which 13 sequences were identical to the LMW-GS genes identified from BAC clones (Dong et al. 2010; Table 2; Fig. 3b). The other four new genes were mapped to the Glu-3 locus by this marker system and by microsatellite markers with a population of recombinant inbred lines derived from a cross between Xiaoyan 54 and Jing 411 (data not shown). Of the 18 unique LMW-GS genes identified in Xiaoyan 54, 6 were located at the Glu$A 3$ locus, 4 at the Glu-B3 locus and 8 at the Glu-D3 locus (Table 2). In Norin 61, 18 unique DNA fragments were identified, with most being identical in size to those from Xiaoyan 54 (Supplementary Table 2). Compared to the sequences reported by Ikeda et al. (2002), 12 DNA fragments could be matched with 12 genes with high similarities in the coding sequences for $\mathrm{N}$-terminal and $\mathrm{C}$-terminal regions, whereas 4 of the genes contained deletions in the repetitive domain, resulting in the different sizes of the corresponding sequences between the report by Ikeda et al. (2002) and the present study (Supplementary Table 2). The other six DNA fragments-460, 499, 590, 655, 675 and 695 (PCR products with LMWGS2) - might have been derived from new LMW-GS genes that were detected and reported for the first time to our knowledge in Norin 61 (Supplementary Table 2). Using the marker system, 16 DNA fragments were isolated from the genomic DNA of Glenlea, while 12 active genes and seven pseudogenes were isolated by Huang and Cloutier (2008). Nine DNA fragments were identical in length with the 12 active genes (Supplementary Table 2) and the other 7 corresponded as expected to the 7 pseudogenes described by Huang and Cloutier (2008). Similar to the situation of fragment 684 in Chinese Spring detected by the marker system, two fragments-492 and 637-have three and two corresponding active genes (EU189090, EU189091 and EU189092; EU189089 and EU189097), respectively, reported by Huang and Cloutier (2008). Sequence alignment revealed that the three active genes-EU189090, EU189092 and EU189097-were unique in GenBank since they contained special single-nucleotide polymorphisms (SNPs) only present in Glenlea. Future experiments should be performed to confirm whether these three genes are universal in bread wheat. In Chinese Spring, of 12 LMW-GS genes 
retrieved from GenBank, 8 were identical in size to the DNA fragments identified by our marker system (Supplementary Table 2), and the other 4 genes were unique, with deletions in the repetitive region that might have been introduced during the PCR process (Masci et al. 1998; Ikeda et al. 2002). These data suggested that 9 LMW-GS genes corresponding to 9 of the 17 DNA fragments might be reported for the first time in Chinese Spring. In summary, the comparison demonstrated that the marker system could help us detect not only most of the LMW-GS genes reported previously, but also some new LMW-GS genes in Xiaoyan 54, Norin 61, Glenlea and Chinese Spring that were not found in other studies. The marker system could potentially be used to identify LMW-GS genes and elucidate the complex of this gene family in bread wheat.

The sizes of the DNA fragments detected in Xiaoyan 54, Chinese Spring, Norin 61 and Glenlea were compared (Supplementary Table 2). The data showed that these varieties shared several genes with the same size of DNA fragments: D3-4 (492), D3-5 (499), D3-7 (501), B3-1 (637), LGS2-655 (655), D3-1 (682) and D3-3 (684). The alignment analysis demonstrated that the sequences of these genes were extremely conserved, with only a few SNPs among different varieties. Allelic variations in the other DNA fragments and their corresponding sequences in GenBank were aligned as well, indicating that allelic variations of a certain gene were also conserved in nucleotide sequences, although certain kinds of deletions were present in each allelic variation. On the other hand, allelic variations of the genes (i.e. LGS2-477, A3-1, LGS2-590, A3-2, A3-3 and A3-4 at the Glu-A3 locus, B3-2 and B3-3 at the Glu-B3 locus, D3-2,D3-6 and LGS2-690 at the Glu-D3 locus) displayed high polymorphism in the length of the repetitive domains (Supplementary Table 2). The allelic variation of $D 3-2$ gene, e.g., corresponded to the DNA fragment 547 in Glu-D3a allele (Chinese Spring), and 538 in Glu-D3c allele (Xiaoyan 54, Norin 61 and Glenlea). These data suggested that the differences in the molecular weight among LMW-GS alleles, which were characterised with SDS-PAGE and MALDI-TOF-MS (Singh et al. 1991; Dworschak et al. 1998; Liu et al. 2010), might also be detected by the developed marker system. Further work is necessary to characterise LMW-GS genes in hundreds of wheat varieties with this developed molecular marker system. Comparison of the composition of the DNA fragments and alignment of the sequences of LMW-GS genes among wheat varieties might deeply display the conservation and polymorphism among allelic variations and facilitate the construction of the relationship between each unique DNA fragment and a specific LMW-GS gene. Thus, this new marker system is useful in characterising the LMW-GS genes and illuminating the composition of this gene family in bread wheat.
Advantages of the new marker system in identifying LMW-GS genes

Combining the conserved primers and capillary electrophoresis, we have provided an efficient marker system to identify LMW-GS genes in bread wheat. Genomic DNA or cDNA from several bread wheat varieties was amplified with the conserved primers, and subsequently, the PCR products were analysed using the Applied Biosystems 3730 DNA Analyzer. This system has advantages over traditional protein-based techniques and other marker systems for identifying LMW-GS genes.

First, the marker system is efficient and applicable to all wheat varieties in identifying LMW-GS genes. Compared to protein-based methods, DNA-based molecular markers are simpler to operate and have been widely used as diagnostic markers for the identification of LMW-GS in bread wheat (D'Ovidio 1993; D'Ovidio and Porceddu 1996; D'Ovidio et al. 1999; Long et al. 2005; Ikeda et al. 2006; Zhao et al. 2006, 2007; Huang and Cloutier 2008; Wang et al. 2009, 2010; Dong et al. 2010). Group-specific markers have been designed based on polymorphic sites of the LMW-GS genes identified in Norin 61 and Glenlea (Ikeda et al. 2006; Huang and Cloutier 2008). These markers might be useful in characterising LMW-GS genes in a special variety, but their efficiency in identifying LMW-GS genes in other varieties has not been validated. Recently, following the analysis of LMW-GS gene sequences in different haplotypes, several sequence-tagged-site (STS) markers for Glu-A3, Glu-B3 and Glu-D3 subunits were developed and validated in $>100$ wheat varieties (Zhao et al. 2006, 2007; Wang et al. 2009, 2010). Additionally, some other gene-specific markers were developed based on polymorphic sites of the cloned LMWGS genes (D'Ovidio 1993; D’Ovidio and Porceddu 1996; D'Ovidio et al. 1999; Dong et al. 2010). However, the LMW-GS gene family in bread wheat was complex and their exact composition was still not well understood (D'Ovidio and Masci 2004; Liu et al. 2010). Thus, the above molecular markers were useful in detecting the known LMW-GS genes, but were limited and difficult in identifying and characterising some other new genes in the LMW-GS gene family in bread wheat. In the present study, we developed a LMW-GS gene molecular marker system based on the conservation and polymorphism among LMW-GS genes. In the marker system, conserved primers ensured the amplification of all the LMW-GS genes in bread wheat, which made the marker system applicable to all wheat varieties, and the high polymorphism in length of the repetitive domain facilitated the separation of the amplified LMW-GS genes by capillary electrophoresis. After conventional PCR using conserved primers, $>10$ DNA fragments could be displayed using the Applied 
Biosystems 3730 DNA Analyzer, and each fragment was determined to be derived from a LMW-GS gene (Figs. 3b, 4a). The marker system has been evaluated using several varieties, in which LMW-GS genes have been investigated (Ikeda et al. 2006; Huang and Cloutier 2008; Dong et al. 2010). Except for the known LMW-GS genes, several new LMW-GS genes and their allelic variations (e.g. LGS2-477, $L G S 2-590$ and LGS2-690) have been identified and reported for the first time.

Second, the marker system is accurate with the use of high-resolution capillary electrophoresis. PCR products using the marker system were separated by high-resolution capillary electrophoresis, which has higher resolution (up to $1 \mathrm{bp}$ ) than traditional agarose or denatured/native polyacrylamide gel electrophoresis. Capillary electrophoresis instruments have been widely used for DNA fragment analysis: e.g. in simple sequence repeat, amplified fragment length polymorphism and DNA footprinting analyses (Maguire et al. 2002; Broza et al. 2007; Zianni et al. 2006). Additionally, with the help of GeneScan 1200 LIZ size standards, the size of DNA fragments can be measured digitally using GeneMapper Software v3.7, which could facilitate further comparison of LMW-GS genes among various varieties.

Third, the marker system is time-saving and high throughput. Conventional PCR and capillary electrophoresis in the marker system are highly automatic, and the run time and subsequent analysis can be completed in $4-5 \mathrm{~h}$ as compared to 2-4 days for protein isolation and subsequent identification. Protein-based methods entail protein isolation and separation, gel spot excision, in-gel digestion, MS analysis and database searching (Mamone et al. 2009; Dong et al. 2010). All these steps add considerable labour and expense to the experiment for LMW-GS identification in one sample, whereas our marker system contains two highly automatic steps: conventional PCR and capillary electrophoresis. Thus, with this marker system, several hundred samples could be easily analysed by one person in 1 day. This marker system does, however, have the disadvantage of being difficult to distinguish active LMW-GS genes in the bread wheat genome, but it is still efficient in identifying LMW-GS genes expressed in developing kernels, such as those shown in Xiaoyan 54 (Supplementary Fig. 2).

In summary, we developed a simple and reliable marker system to elucidate the complex LMW-GS gene family in bread wheat. The molecular marker system comprises the use of conserved primers for LMW-GS genes and highresolution capillary electrophoresis and was confirmed to be efficient in characterising LMW-GS genes in Xiaoyan 54, Norin 61, Glenlea and Chinese Spring. Thus, the marker system, involving conserved primers and capillary electrophoresis, is valid and powerful to elucidate the members of the LMW-GS gene family in bread wheat. In near future, the marker system may help to improve the characterisation of LMW-GS genes in numerous bread wheat varieties and its relatives and to facilitate the establishment of a clear relationship between the allelic variations in LMW-GS genes and bread-making quality in wheat.

Acknowledgments We thank Drs Xianchun Xia (Chinese Academy of Agricultural Sciences, Beijing, China) and Xiuqiang Huang (University of Manitoba, Winnipeg, Canada) for constructive suggestions on this work. This work was supported by the Ministry of Science and Technology of China (2009CB118300 and 2006AA10Z1B2) and the Ministry of Agriculture of China for transgenic research (2008ZX08009-003 and 2008ZX08002-004).

Open Access This article is distributed under the terms of the Creative Commons Attribution Noncommercial License which permits any noncommercial use, distribution, and reproduction in any medium, provided the original author(s) and source are credited.

\section{References}

Akbari A, Marthinsen G, Lifjeld JT, Albregtsen F, Wennerberg L, Stenseth NC, Jakobsen KS (2008) Improved DNA fragment length estimation in capillary electrophoresis. Electrophoresis 29:1273-1285

Amiour N, Merlino M, Leroy P, Branlard G (2002) Proteomic analysis of amphiphilic proteins of hexaploid wheat kernels. Proteomics 2:632-641

An X, Zhang Q, Yan Y, Li Q, Zhang Y, Wang A, Pei Y, Tian J, Wang $\mathrm{H}$, Hsam SLK, Zeller FJ (2006) Cloning and molecular characterization of three novel LMW-i glutenin subunit genes from cultivated einkorn (Triticum monococcum L.). Theor Appl Genet 113:383-395

Andon NL, Hollingworth S, Koller A, Greenland AJ, Yates JR III, Haynes PA (2002) Proteomic characterization of wheat amyloplasts using identification of proteins by tandem mass spectrometry. Proteomics 2:1156-1168

Balmer Y, Vensel WH, DuPont FM, Buchanan BB, Hurkman WJ (2006) Proteome of amyloplasts isolated from developing wheat endosperm presents evidence of broad metabolic capability. J Exp Bot 57:1591-1602

Broza YY, Danin-Poleg Y, Lerner L, Broza M, Kashi Y (2007) Vibrio vulnificus typing based on simple sequence repeats: insights into the biotype 3 group. J Clin Microbiol 45:2951-2959

Butler JM, Buel E, Crivellente F, McCord BR (2004) Forensic DNA typing by capillary electrophoresis using the ABI Prism 310 and 3100 genetic analyzers for STR analysis. Electrophoresis 25:1397-1412

Cassidy BG, Dvorak J, Anderson OD (1998) The wheat lowmolecular-weight glutenin genes: characterization of six new genes and progress in understanding gene family structure. Theor Appl Genet 96:743-750

D'Ovidio R (1993) Single-seed PCR of LMW glutenin genes to distinguish between durum wheat cultivars with good and poor technological properties. Plant Mol Biol 22:1173-1176

D'Ovidio R, Masci S (2004) The low-molecular-weight glutenin subunits of wheat gluten. J Cereal Sci 39:321-339

D’Ovidio R, Porceddu E (1996) PCR-based assay for detecting 1Bgenes for low molecular weight glutenin subunits related to 
gluten quality properties in durum wheat. Plant Breed 115:413-415

D’Ovidio R, Marchitelli C, Ercoli Cardelli L, Porceddu E (1999) Sequence similarity between allelic $G l u-B 3$ genes related to quality properties of durum wheat. Theor Appl Genet 98:455-461

Dong LL, Zhang XF, Liu DC, Fan HJ, Sun JZ, Zhang ZJ, Qin HJ, Li B, Hao ST, Li ZS, Wang DW, Zhang AM, Ling HQ (2010) New insights into the organization, recombination, expression and functional mechanism of low molecular weight glutenin subunit genes in bread wheat. PLoS One 5(10):e13548. doi: 10.1371/journal.pone. 0013548

Dworschak RG, Ens W, Standing KG, Preston KR, Marchylo BA, Nightingale MJ, Stevenson SG, Hatcher DW (1998) Analysis of wheat gluten proteins by matrix-assisted laser desorption/ionization mass spectrometry. J Mass Spectrom 33:429-435

Gupta RB, Shepherd KW (1990) Two-step one-dimensional SDSPAGE analysis of LMW subunits of glutelin. 1. Variation and genetic control of the subunits in hexaploid wheats. Theor Appl Genet 80:65-74

Gupta RB, Singh NK, Shepherd KW (1989) The cumulative effect of allelic variation in LMW and HMW glutenin subunits on dough properties in the progeny of two bread wheats. Theor Appl Genet 77:57-64

Gupta RB, Békés F, Wrigley CW (1991) Prediction of physical dough properties from glutenin subunit composition in bread wheats: correlation studies. Cereal Chem 68:328-333

Harberd NP, Bartels D, Thompson RD (1985) Analysis of the gliadin multigene loci in bread wheat using nullisomic-tetrasomic lines. Mol Gen Genet 198:234-242

Huang XQ, Cloutier S (2008) Molecular characterization and genomic organization of low molecular weight glutenin subunit genes at the Glu-3 loci in hexaploid wheat (Triticum aestivum L.). Theor Appl Genet 116:953-966

Ikeda TM, Nagamine T, Fukuoka H, Yano H (2002) Identification of new low-molecular-weight glutenin subunit genes in wheat. Theor Appl Genet 104:680-687

Ikeda TM, Araki E, Fujita Y, Yano H (2006) Characterization of lowmolecular-weight glutenin subunit genes and their protein products in common wheats. Theor Appl Genet 112:327-334

Liu L (2008) Identification of glutenin composition in common wheat by proteomics technology. Institute of Crop Science, Chinese Academy of Agricultural Sciences, Beijing

Liu L, Ikeda TM, Branlard G, Peña RJ, Rogers WJ, Lerner SE, Kolman MA, Xia XC, Wang LH, Ma WJ, Appels R, Yoshida H, Wang AL, Yan YM, He ZH (2010) Comparison of low molecular weight glutenin subunits identified by SDS-PAGE, 2-DE, MALDI-TOF-MS and PCR in common wheat. BMC Plant Biol. doi:10.1186/1471-2229-10-124

Long H, Wei YM, Yan ZH, Baum B, Nevo E, Zheng YL (2005) Classification of wheat low-molecular-weight glutenin subunit genes and its chromosome assignment by developing LMW-GS group-specific primers. Theor Appl Genet 111:1251-1259

Maguire TL, Peakall R, Saenger P (2002) Comparative analysis of genetic diversity in the mangrove species Avicennia marina (Forsk.) Vierh. (Avicenniaceae) detected by AFLPs and SSRs. Theor Appl Genet 104:388-398

Mamone G, De Caro S, Di Luccia A, Addeo F, Ferranti P (2009) Proteomic-based analytical approach for the characterization of glutenin subunits in durum wheat. J Mass Spectrom 44:1709-1723

Margiotta B, Colaprico G, D’Ovidio R, Lafiandra D (1993) Characterization of high $\mathrm{Mr}$ subunits of glutenin by combined chromatographic (RP-HPLC) and electrophoretic separations and restriction fragment length polymorphism (RFLP) analyses of their encoding genes. J Cereal Sci 17:221-236

Masci S, D'Ovidio R, Lafiandra D, Kasarda DD (1998) Characterization of a low-molecular-weight glutenin subunit gene from bread wheat and the corresponding protein that represents a major subunit of the glutenin polymer. Plant Physiol 118:1147-1158

Metakovsky EV, Wrigley CW, Békés F, Gupta RB (1990) Gluten polypeptides as useful genetic markers of dough quality in Australian wheats. Aust J Agric Res 41:289-306

Osborne TB (1924) The vegetable proteins. Longmans Green and Co., London

Payne PI (1987) Genetics of wheat storage proteins and the effect of allelic variation on bread-making quality. Ann Rev Plant Physiol 38:141-153

Rosenblum BB, Oaks F, Menchen S, Johnson B (1997) Improved single-strand DNA sizing accuracy in capillary electrophoresis. Nucleic Acids Res 25:3925-3929

Sabelli PA, Shewry PR (1991) Characterization and organization of gene families at the Gli-1 loci of bread and durum wheats by restriction fragment analysis. Theor Appl Genet 83:209-216

Saghai-Maroof MA, Soliman KM, Jorgensen RA, Allard RW (1984) Ribosomal DNA spacer-length polymorphisms in barley: Mendelian inheritance, chromosomal location, and population dynamics. Proc Natl Acad Sci USA 81:8014-8018

Shewry PR, Tatham AS, Barro F, Barcelo P, Lazzeri P (1995) Biotechnology of breadmaking: unraveling and manipulating the multi-protein gluten complex. Nat Biotechnol 13:1185-1190

Singh NK, Shepherd KW (1988) Linkage mapping of genes controlling endosperm storage proteins in wheat. 1. Genes on the short arms of group 1 chromosomes. Theor Appl Genet 75:628-641

Singh NK, Shepherd KW, Cornish GB (1991) A simplified SDSPAGE procedure for separating LMW subunits of glutenin. J Cereal Sci 14:203-208

Tamura K, Dudley J, Nei M, Kumar S (2007) MEGA4: Molecular Evolutionary Genetics Analysis (MEGA) software version 4.0. Mol Biol Evol 24:1596-1599

Wang LH, Zhao XL, He ZH, Ma W, Appels R, Peña RJ, Xia XC (2009) Characterization of low-molecular-weight glutenin subunit Glu-B3 genes and development of STS markers in common wheat (Triticum aestivum L.). Theor Appl Genet 118:525-539

Wang LH, Li GY, Peňa RJ, Xia XC, He ZH (2010) Development of STS markers and establishment of multiplex PCR for Glu-A3 alleles in common wheat (Triticum aestivum L.). J Cereal Sci $51: 305-312$

Weegels PL, Hamer RJ, Schofield JD (1996) Functional properties of wheat glutenin. J Cereal Sci 23:1-17

Zhang W, Gianibelli MC, Rampling LR, Gale KR (2004) Characterization and marker development for low molecular weight glutenin genes from Glu-A3 alleles of bread wheat (Triticum aestivum L.). Theor Appl Genet 108:1409-1419

Zhao XL, Xia XC, He ZH, Gale KR, Lei ZS, Appels R, Ma W (2006) Characterization of three low-molecular-weight Glu-D3 subunit genes in common wheat. Theor Appl Genet 113:1247-1259

Zhao XL, Xia XC, He ZH, Lei ZS, Appels R, Yang Y, Sun QX, Ma W (2007) Novel DNA variations to characterize low molecular weight glutenin Glu-D3 genes and develop STS markers in common wheat. Theor Appl Genet 114:451-460

Zianni M, Tessanne K, Merighi M, Laguna R, Tabita FR (2006) Identification of the DNA bases of a DNase I footprint by the use of dye primer sequencing on an automated capillary DNA analysis instrument. J Biomol Tech 17:103-113 